\title{
Design of Magnetic Polymeric Particles as a Stimulus-Responsive System for Gastric Antimicrobial Therapy
}

Erica L. Silva-Freitas, ${ }^{1,2}$ Thales R. F. Pontes, ${ }^{2}$ Rafael P. Araújo-Neto, ${ }^{2}$ Ítalo H. M. Damasceno, ${ }^{2}$ Kátia L. Silva, ${ }^{2}$ Juliana F. Carvalho, ${ }^{2}$ Aldo C. Medeiros, ${ }^{3}$ Rodolfo B. Silva, ${ }^{4}$ Amanda K. A. Silva, ${ }^{5}$ Marco A. Morales, ${ }^{4}$ Eryvaldo S. T. Egito, ${ }^{2}$ Ana L. Dantas, ${ }^{6}$ and Artur S. Carriço ${ }^{4,7}$

Received 19 August 2016; accepted 14 November 2016; published online 13 December 2016

\begin{abstract}
The treatment of peptic ulcers induced by H. pylori remains challenging due to the deep mucous layer location of bacteria preventing antimicrobial drug access. The present work aimed to design and evaluate in vitro dual responsive (both $\mathrm{pH}$ and magnetic fieldsensitive) polymeric magnetic particles loaded with amoxicillin as a smart drug carrier for deep mucous layer penetration and in situ drug release. Magnetite particles were produced by the co-precipitation method and subsequently coated with the Eudragit ${ }^{\circledR} \mathrm{S} 100$ and amoxicillin by using the spray-drying technique. The physicochemical characterization of the obtained particles was carried out by optical and scanning electron microscopy, X-ray powder diffraction, Fourier transform infrared spectroscopy, nitrogen adsorption/desorption isotherms, and vibrating sample magnetometry. Additionally, drug release tests and antibacterial activity tests were evaluated in vitro. Microparticles presented $17.2 \pm 0.4 \mu \mathrm{m}$ in size and their final composition was $4.3 \pm 1.5 \%$ of amoxicillin, $87.0 \pm 2.3 \%$ of Eudragit, and $9.0 \pm 0.3 \%$ of magnetite. They were both $\mathrm{pH}$ and magnetic field responsive while presenting antimicrobial activity. On one side, magnetic field responsiveness of particles is expected to prompt them to reach bacterium niche in deep mucous layer by means of magnetic forces. On the other side, $\mathrm{pH}$ responsiveness is expected to enable drug release in the neutral $\mathrm{pH}$ of the deep mucous layer, preventing undesired delivery in the acidic gastric lumen. Smart microparticles were designed presenting both $\mathrm{pH}$ and magnetic field responsiveness as well as antimicrobial activity. These may be promising assets for peptic ulcer treatment.
\end{abstract}

KEY WORDS: antimicrobial activity; drug delivery; magnetite; smart microsystems; spray drier.

\section{INTRODUCTION}

Helicobacter pylori (H. pylori) are characterized by gramnegative staining, spiral shape, and the presence of polar flagella. H. pylori are the only known organism able to colonize

${ }^{1}$ Departamento de Análises de Produtos e Ambiente, Setor de Análise de Medicamentos, Laboratório Central Dr. Almino Fernandes, Natal, RN, Brazil.

${ }^{2}$ Departamento de Farmácia, Universidade Federal do Rio Grande do Norte, Natal, RN, Brazil.

${ }^{3}$ Departamento de Cirurgia, Universidade Federal do Rio Grande do Norte, Natal, RN, Brazil.

${ }^{4}$ Departamento de Física Teórica e Experimental, Universidade Federal do Rio Grande do Norte, UFRN, Avenida Senador Salgado Filho, 3000, 59078-970, Natal, RN, Brazil.

${ }^{5}$ Laboratoire Matière et Systèmes Complexes, UMR 7057, CNRS, Université Paris Diderot, Paris, France.

${ }^{6}$ Departamento de Física, Universidade do Estado do Rio Grande do Norte, Mossoró, RN, Brazil.

${ }^{7}$ To whom correspondence should be addressed. (e-mail: ascarrico@gmail.com) the harsh gastric environment in humans, living near the gastric mucosa surface. Most of infected subjects are asymptomatic. Nevertheless, infection may induce significant human disease (1). Over the past two decades, research efforts have been focused on the investigation of effective treatment strategies for healing $H$. pylori infection. The main difficulty relates to the localization of the bacteria on gastric mucosa surface and the presence of a protective mucus layer (2).

Although $H$. pylori is susceptible to several antibiotics in vitro, in vivo eradication is quite challenging (3). Amoxicillin is considered a well-tolerated beta-lactam antibiotic displaying a broad-spectrum of action, which renders possible the therapy of many bacterial infections, including $H$. pylori. Amoxicillin acts during $H$. pylori proliferation phase by inhibiting the biosynthesis of the cell wall at $\mathrm{pH} 5$ and above, being considered the first line drug along with metronidazole or clarithromycin, and omeprazole for peptic and duodenal ulcer therapy induced by $H$. pylori (4). H. pylori are able to penetrate into the layer of gastric mucus and attach to it via phospholipids and glycolipids present in the mucus gel (5), restricting the access of antimicrobial drugs to the infection 
site. Considering that amoxicillin presents a short gastric residence time and that it may be degraded in the gastric acid, blood levels are reduced, which render difficult $H$. pylori eradication (6). Therefore, the design of drug delivery systems endowed with extended residence time and able to attain the infection site under the mucus layer is required.

Mucus represents a very complex hydrogel constituted by carbohydrates, proteins, lipids, antibodies, salts, and bacteria as well as cellular debris. In humans, mucus confers protection from acid in the stomach. Its thickness is of about $180 \mu \mathrm{m}$ (ranging from 40 to $450 \mu \mathrm{m}$ ) (7). Mucus $\mathrm{pH}$ in the stomach varies from 1 to 2 at the lumen surface, while it is nearly neutral at the epithelium level. Therefore, there is a gradient from $\mathrm{pH} 1-2$ to $\mathrm{pH} 7$ through a mucus thickness of only $180 \mu \mathrm{m}$. Such a gradient occurs as gastric mucus acts as a selective barrier limiting acid diffusion. Mucus-penetrating particles are expected to improve drug delivery by passing through the first part of mucus layer, which is loosely adherent and rapidly cleared, in the attempt to be retained in the next part, which is the firmly adherent one $(8,9)$.

In the last 20 years, several gastroretentive dosage forms have been investigated in order to extend gastric residence time $(10,11)$. They broadly fall into the following categories: sinking (high-density) systems (12), floating (low-density) systems (13), expandable systems (14), hydrogels (15), mucoadhesive systems (16), and magnetically actuated systems (17).

Magnetic drug targeting (MDT) may represent an efficient strategy to address drugs associated to a magnetic carrier to a specific target site located at the gastrointestinal tract via an external magnetic field (18). The magnetic field is expected to slow down the speed of travel of drug-loaded magnetic carrier, thereby, modulating its position, its residence time, and drug absorption extent in the stomach or intestines (19). Magnetic vectorization allows a large concentration drug delivery at the site of the infection. Therefore, even for a drug which may be stable in acid environment, a much better therapeutic efficiency may be achieved by means of the magnetic vectorization. A key point in the design of magnetic systems for local drug delivery is the strength of the magnetic force, such as to tailor how far deep can the external magnetic field reach, driving the drug to the site of action. Using suitable rare-earth magnets, the magnetic force (20) can be strong enough to overcome the peristaltic motion and the barrier for mucus layer penetration.

Maghemite $\left(\gamma-\mathrm{Fe}_{2} \mathrm{O}_{3}\right)$ as well as magnetite $\left(\mathrm{Fe}_{3} \mathrm{O}_{4}\right)$ are suitable to be used in biomedical application due to their biological properties, high magnetic moment, superparamagnetic behavior, and controllable size parameters (21). Magnetite is one of the iron oxides that received the approval from the Food and Drug Administration (FDA) (22).

In addition to magnetic field responsiveness, nanoparticles may be endowed with $\mathrm{pH}$ responsiveness in the attempt to obtain a controlled drug release effect in the gastrointestinal tract. A number of different approaches have been proposed so far, including coating with $\mathrm{pH}$-sensitive polymers (23). Eudragit ${ }^{\circledR} \mathrm{S} 100$ is a methacrylic acid and methyl methacrylate ester copolymer. It represents the most widely employed $\mathrm{pH}$-responsive polymer in order to achieve drug release at the ileo-colonic region due to its solubility at $\mathrm{pH} 7.0$ (Rohm Pharma, Darmstadt, Germany).
The objectives of this study were to synthesize and characterize magnetite particles coated with Eudragit ${ }^{\circledR} \mathrm{S} 100$ and amoxicillin in order to design a dual magnetic and $\mathrm{pH}-$ responsive system for deep mucous layer penetration and in situ antibiotic release. In an unprecedented strategy, the magnetic responsiveness of nanoparticles is expected to constrain the penetration of the system across the mucus while the Eudragit ${ }^{\circledR} \mathrm{S} 100$ coating is expected to allow optimal drug delivery in the deep mucous ( $\mathrm{pH} 7$ ) niche of $H$. pylori.

\section{MATERIALS AND METHODS}

\section{Materials}

Ferric chloride hexahydrate (Acros Organics, Brazil; P.A.); ferrous sulfate heptahydrate (Acros Organics, USA; $99 \%$ ), sodium hydroxide $(\mathrm{NaOH})$ (Vetec chemical, Brazil; 99\%), hydrochloric acid $(\mathrm{HCl})$ (Vetec Chemical, Brazil; $37 \%$ ), amoxicillin (Galena, Brazil; 97\%), Eudragit ${ }^{\circledR} \mathrm{S} 100$ (Rohm Gmbh \& cokg, German; methacrylic acid-methyl methacrylate copolymer 1:2), and phosphate buffer $\mathrm{pH} 7.4$ were of pharmaceutical grade and used as received without further purification.

The culture medium for bacterium was purchased from HiMedia Laboratories, Brazil. The selected bacterial strain was the Micrococcus luteus ATCC 9341, which was obtained from the Fundação Oswaldo Cruz (Fiocruz/RJ, Brazil). Nutrient agar was employed in order to enable bacterial strain growth and maintenance. Suspension cultures were prepared using nutrient broth. Antibacterial activity of magnetic system was assessed in Tripcase-Soy Agar (TSA).

\section{Synthesis of Magnetic Particles (MPs)}

The MP synthesis was based on the co-precipitation method (24). MPs were prepared as follows. Ferric chloride hexahydrate $\left(\mathrm{FeCl}_{3} \cdot 6 \mathrm{H}_{2} \mathrm{O}\right)$ at $0.1 \mathrm{M}$ and ferrous sulfate heptahydrate $\left(\mathrm{Fe}_{2} \mathrm{SO}_{4} .7 \mathrm{H}_{2} \mathrm{O}\right)$ at $0.05 \mathrm{M}$ solutions in $0.1 \mathrm{M}$ $\mathrm{HCl}$ were prepared. In brief, $9 \mathrm{~mL}$ of ferrous and ferric salt mixture was added drop-wise into $300 \mathrm{~mL}$ of $\mathrm{NaOH}$ solution at $1 \mathrm{M}$ concentration under bath sonication (Unique USC 1800, $40 \mathrm{kHz}$, Brazil). Vigorous mechanical stirring at $960 \mathrm{rpm}$ (IKA RW-20, Germany) was carried out for $30 \mathrm{~min}$ at room temperature $\left(25^{\circ} \mathrm{C}\right)$. The color of the reagent mixture shifted from orange to black forming a dark precipitate. After decantation, the supernatant was discarded and the precipitate was washed three times to remove excess of $\mathrm{Fe}$ and $\mathrm{Na}$ ions in the suspension. Finally, the precipitate obtained after washing was dried in the oven for further investigation.

\section{Production of Magnetic Polymeric Particles (With and Without Amoxicillin)}

Polymeric magnetic microparticles with amoxicillin (hereafter labeled as MagAmox) were produced by the spray-drying technique (25). To obtain the MagAmox, $750 \mathrm{mg}$ of Eudragit ${ }^{\circledR} \mathrm{S} 100$ was dispersed in a $\mathrm{NaOH}$ solution $0.4 \mathrm{~N}(90 \mathrm{~mL})$ and $300 \mathrm{mg}$ of amoxicillin was dispersed in distilled water $(90 \mathrm{~mL})$. The dispersions were mixed under mechanic stirring at $960 \mathrm{rpm}$ and $7.5 \mathrm{~mL}$ of the magnetite suspension $(40 \mathrm{mg} / \mathrm{mL})$, previously subjected to ultrasound 
bath for $5 \mathrm{~min}$ (Unique USC 1800, $40 \mathrm{kHz}$, Brazil), was added. The blank sample (MagEud), containing only Eudragit ${ }^{\circledR}$ S100 and MP, was prepared. The preparation was thus maintained in moderate agitation and fed into the spraydryer (Mini Spray-dryer Büchi B191, Germany). The device was equipped with a two-fluid nozzle, providing particles from 2 to $25 \mu \mathrm{m}$. The residence time of the drying air within the spray chamber was of about $1.5 \mathrm{~s}$. The flow rate was $1.2 \mathrm{~mL} / \mathrm{min}$ (inlet temperature of $120^{\circ} \mathrm{C}$ ) using a peristaltic pump. Once recovered, the dried powders were weighed and, then, they were stored at room temperature in a hermetically closed glass vessel.

\section{Characterization of the Obtained Particles}

\section{$X$-ray Diffraction $(X R D)$}

X-ray diffractometer (Shimadzu, XRD-6000, Japan) was used to analyze the structural properties of MPs. This measurement was performed to characterize the nanocrystalline structure and identify the iron oxide specie. Representative powder sample was analyzed in the range $20^{\circ}<2 \theta<70^{\circ}$ by using the $\mathrm{CuK} \alpha$ radiation with wavelength of $1.54056^{\circ} \AA$.

\section{Size and Morphology Studies}

MP and MagAmox were subjected to particle size analysis under optical microscopy (Leica microscopic). The samples were added to glass slides and the size of 1500 microparticles of each condition were measured in accordance to Ferret's method using a stage micrometer scale for calibration (26). Size analysis as well as morphology investigation were also checked using a scanning electron microscope (SEM, XL 30 ESEM, Philips, The Netherlands).

\section{Surface Area and Porosity Evaluation}

Isotherms of nitrogen adsorption-desorption (NSD) at $77 \mathrm{~K}$ were recorded on an ASAP 2420/Micromeritics Instrument. Standard Brunauer-Emmett-Teller (BET) procedure was employed in order to obtain the specific surface area $\left(\mathrm{S}_{\mathrm{BET}}\right)$ of the analyzed powder samples. Barrett-JoynerHalenda $(\mathrm{BJH})$ method was used for calculating the distribution of pore size (27).

\section{Vibrating Sample Magnetometry (VSM) Evaluation}

Magnetization measurements of the MP and MagAmox samples in powder form were carried out by means of a homemade vibrating sample magnetometer after a calibration step using a nickel sample. Measurements of magnetization as a function of the applied field were obtained at room temperature using $1.17 \mathrm{~T}$ maximum applied field.

\section{Fourier Transform Infrared Spectroscopy (FTIR)}

The sample spectra of FTIR transmission were obtained with a Perkin-Elmer spectrometer (Spectrum 65 FTIR Spectrometer, Perkin-Elmer, Buckinghamshire, U.K.), operating with spectrum v3.02 software. Pellets for FTIR analysis were prepared by mixing the samples with spectroscopic grade $\mathrm{KBr}$ powder, $2 \mathrm{mg}$ of each sample were mixed with $200 \mathrm{mg}$ of $\mathrm{KBr}$ thoroughly mixed and pressed to obtain a pellet. The FTIR spectra were obtained in the transmission mode using 400-4000 $\mathrm{cm}^{-1}$ range at a $1 \mathrm{~cm}^{-1}$ resolution.

\section{Amoxicillin and Magnetite Content Assay}

For this experiment, $250 \mathrm{mg}$ of MagAmox was added to $100 \mathrm{ml}$ of ethanol to dissolve the polymeric matrix (Eudragit ${ }^{\circledR} \mathrm{S} 100$ ) and centrifugation was performed to separate magnetite microparticles. The amoxicillin content was determined with an UV/vis spectrophotometer (Liochrom Libra S32, UK), and the measurements were carried out at $233 \mathrm{~nm}$ wavelength. The analysis was performed in triplicate. The dissolution of the precipitate was carried out in a $0.1 \mathrm{M} \mathrm{HCl}$ solution previously to the determination of magnetite content. Then, the iron ions were complexed with sulfosalicylic acid. Absorbance was, then, measured at $420 \mathrm{~nm}$ wavelength (28). For validation, a calibration curve for amoxicillin or iron was generated.

\section{Drug Release Assay}

Amoxicillin release from the MagAmox was investigated via a dissolution test according to USP XXIV (United States Pharmacopeia) by using a dedicated type II paddle dissolution device (model 299-6, Ethik Tehcnologies). Paddle speed was set at $100 \mathrm{rpm}$ and the tests were carried out in triplicate in $500 \mathrm{ml}$ of dissolution medium kept at $37.0 \pm 0.5^{\circ} \mathrm{C}$. The investigation of drug release from MagAmox sample was conducted at $\mathrm{pH} 1.2$ in a $0.1 \mathrm{~N} \mathrm{HCl}$ solution during $2 \mathrm{~h}$ as well as at pH 7.4 in buffer media (phosphate buffer) for another $2 \mathrm{~h}$.

Phosphate buffer was prepared according to United States Pharmacopeia (USP 27, 2004) by placing $250 \mathrm{~mL}$ of the $0.2 \mathrm{M}$ monobasic potassium phosphate solution in a $1000 \mathrm{~mL}$ volumetric flask. In addition, $195.5 \mathrm{ml}$ of $0.2 \mathrm{M}$ $\mathrm{NaOH}$ solution was added and the volume was adjusted to $1000 \mathrm{~mL}$ using purified water (if needed, $\mathrm{pH}$ was adjusted with $2 \mathrm{~N} \mathrm{NaOH}$ or $2 \mathrm{~N} \mathrm{HCl}$ ).

Dissolution media were prepared immediately before utilization with deionized water, which was de-aerated prior to use. Dissolution medium aliquots $(2 \mathrm{ml})$ were withdrawn at predetermined time points and were filtered by means of Millipore $0.45 \mu \mathrm{m}$ filter. Drug released was, then, assessed at $233 \mathrm{~nm}$ using UV/vis spectrophotometry. For validation, a calibration curve for amoxicillin was generated.

\section{Antibacterial Activity Assay}

An adapted agar diffusion protocol was performed for the qualitative antimicrobial activity screening in vitro (29), with $M$. luteus being used as the assay microorganism $(30,31)$. The sterilized medium was melted at $100^{\circ} \mathrm{C}$ and after cooling to $46^{\circ} \mathrm{C}$, it was poured onto plates, $(18 \mathrm{~mL}, 90 \mathrm{~mm})$ and left to solidify. M. luteus were obtained in frozen form from the Fiocruz/RJ, Brazil. Bacteria were thawed for $20 \mathrm{~min}$ before being plated on an agar plate. The bacterial cultures were kept in the nutrient agar at $35^{\circ} \mathrm{C}$ for $24 \mathrm{~h}$. After that, bacterial suspensions were prepared by taking 3-5 well separated colonies from agar nutrient plates into $3 \mathrm{ml}$ of saline, and the 
suspension turbidity was set to about $0.5 \mathrm{McF}$ arland standard. The suspension sample was inoculated into TSA plates and distributed homogeneously. Plates were allowed to rest for $10 \mathrm{~min}$ to enable the culture to be absorbed. In order to investigate the antimicrobial activity of MagAmox, $8 \mathrm{~mm}$ wells were carefully punched into the TSA plates. Using a micropipette, $30 \mu \mathrm{L}$ of MagAmox suspensions were added, at different concentrations $(50,100$, and $200 \mu \mathrm{g} / \mathrm{mL})$, on the solid culture medium to which the microbial inoculum was previously seeded. The inoculated plates were incubated for $24 \mathrm{~h}$ at $35^{\circ} \mathrm{C}$. The diameter (in $\mathrm{mm}$ ) of the growth inhibition zones was measured to assess antimicrobial activity.

\section{Statistics}

Measurements were carried out in triplicate with error bars representing standard deviation from the mean. Unpaired $t$ test with Welch's correction was performed using the Prism 3.0 version of GraphPad software (USA). A minimum of $95 \%$ confidence level was considered significant. *, **, and $* * *$ indicates $p<0.05, p<0.01$, and $p<0.001$, respectively.

\section{RESULTS}

\section{X-ray Diffraction Evaluation}

The XRD pattern of the MP displayed peaks that could be attributed either to maghemite $\left(\gamma-\mathrm{Fe}_{2} \mathrm{O}_{3}\right)$ or to magnetite $\left(\mathrm{Fe}_{3} \mathrm{O}_{4}\right)$. These iron oxide compounds consist of ferrites presenting inverse spinel structure. X-ray diffraction is not an appropriate tool to distinguish these iron oxides due to their structural similarities (32). XRD peaks are labeled with magnetite indexes in Fig. 1. The diffractogram consists of wide peaks relative to an elastic coherence volume of $6.5 \mathrm{~nm}$. The particles consist of nano-crystallites that aggregate forming microparticles (see in the next section) displaying superparamagnetic properties, which are suitable for biomedical use.

\section{Size and Morphology Studies}

As shown in Fig. 2, MP and MagAmox displayed a multimodal distribution with a right tail. MP presented a

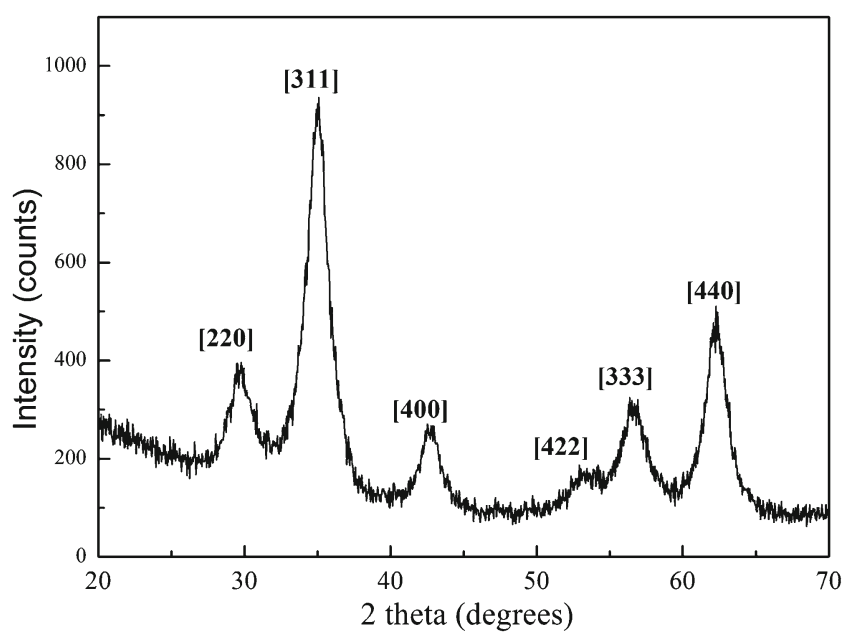

Fig. 1. X-ray diffraction patterns of the MP mean diameter of $11.8 \pm 0.7 \mu \mathrm{m}$. Data showed that 90,50 , and $10 \%$ of the sample was at a size inferior to $20.4 \pm 1.4,10.0 \pm$ 0.7 , and $6.0 \pm 0.6 \mu \mathrm{m}$, respectively. On the other hand, the MagAmox mean diameter was of $17.2 \pm 0.4 \mu \mathrm{m}$ with 90,50 , and $10 \%$ of the sample at a size smaller than $27.6 \pm 0.8,16.4 \pm$ 0.5 , and $9.2 \pm 0.5 \mu \mathrm{m}$, respectively. Particle size increase and changes in morphology, as attested by scanning electron microscopy pictures in Fig. 3, converge to indicate that MPs were coated by the Eudragit ${ }^{\circledR}$ S100. They appeared to be concave and shriveled in a manner that is typically related to the particles derived from macromolecules after the spraydrying process (33).

\section{Surface Area and Porosity Evaluation}

Examination of the samples by NSD resulted in type IV isotherms for MP and type III isotherms for MagAmox (Fig. 4). From these curves, the $\mathrm{S}_{\mathrm{BET}}$ for MP and MagAmox were determined and the values obtained were equal to 252 and $202 \mathrm{~m}^{2} / \mathrm{g}$, respectively. According to the BJH method, the maximum diameters for the MP and MagAmox pores were 5 and $3 \mathrm{~nm}$, respectively. Figure 5 shows that the pore size distribution for MagAmox is narrower when compared with MP particles. From a molecular modeling, it was obtained that the amoxicillin molecule size was about $1.1 \mathrm{~nm}$ (34). The smaller pore diameter in MagAmox may be related to the chemisorption of amoxicillin on the pores of the MP core. Indeed, it will reduce the pore size in about $2 \mathrm{~nm}$ giving a final diameter of about $3 \mathrm{~nm}$. Pore diameters between 2 and $50 \mathrm{~nm}$ are called mesopores according to the IUPAC classification. The potential use of mesoporous materials to enhance the permeability of large hydrophilic drugs has been investigated (35). Furthermore, mesoporous materials offer the possibility to increment the dissolution of poorly soluble drugs via chemical interactions with the surface of the pore (36). When pore size is close to the drug molecule size, the formation of crystalline material is prevented by its confinement within the pore, thus maintaining the drug molecule in its noncrystalline, amorphous form (37).

\section{Vibrating Sample Magnetometry Evaluation}

VSM results showed a reversible hysteresis behavior and a zero coercivity attesting the superparamagnetic nature of the MP (Fig. 6), meaning that these particles do not retain any magnetism when the magnetic field is removed. The saturation magnetization (Ms) for the MagAmox formulation was found to be $4 \mathrm{emu} / \mathrm{g}$. This value is inferior to the MP saturation magnetization $(\mathrm{Ms}=44 \mathrm{emu} / \mathrm{g})$, as expected, considering that there is no contribution to the magnetic moment from the drug and the polymer. The magnetization measurement suggests that the MagAmox has approximately $8 \%$ of the MP in weight. The magnetite magnetization curve has been fitted using the particle size distribution shown in the upper left corner inset. It corresponds to nanoparticles with average diameter of $6.15 \mathrm{~nm}$ and the most probable value of $5.72 \mathrm{~nm}$. Note that with the dipolar interaction (gray line curve) the initial susceptibility is larger than the one without interactions. With the inclusion of the dipolar interaction between the nanoparticles a nice fitting of the measured magnetization curve was achieved. 

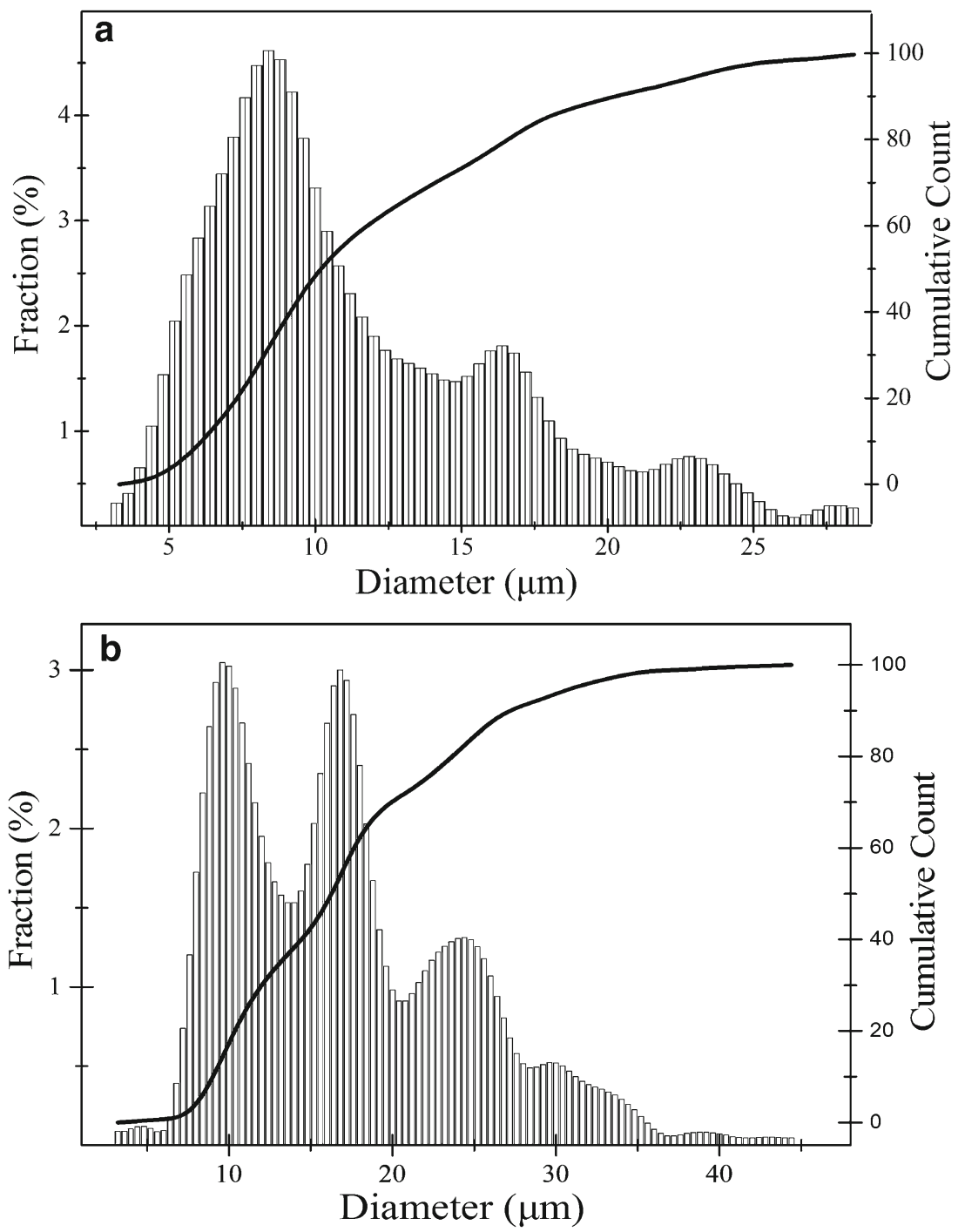

Fig. 2. Size distribution of a magnetite particles and $\mathbf{b}$ MagAmox

\section{Fourier Transform Infrared Spectroscopy}

The aim of the FTIR analysis was to confirm the adsorption of amoxicillin in MagAmox. These analyses were performed for individual components (MP, amoxicillin and Eudragit ${ }^{\circledR}$ S100); MagAmox; and the solution of MP and amoxicillin (sMP/amoxicillin). The sMP/amoxicillin sample was prepared by mixing MP and amoxicillin in an alkaline solution at room temperature. The drug-loaded MPs were separated from the unentrapped drug using a

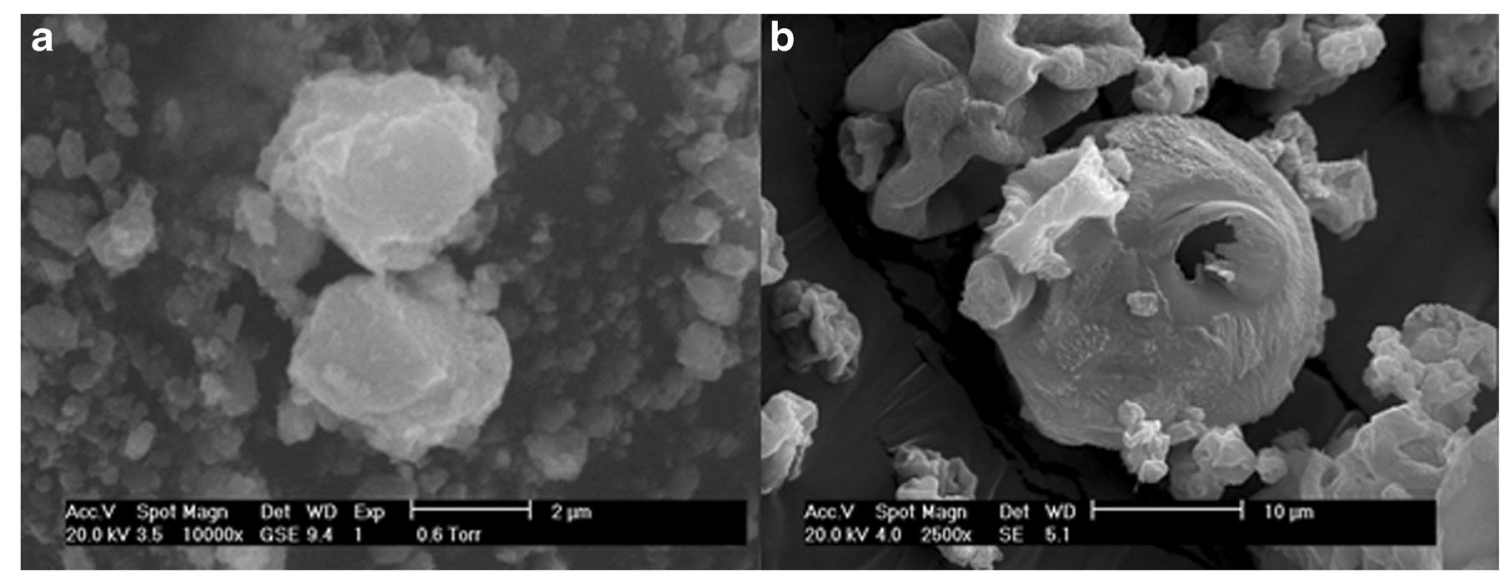

Fig. 3. Scanning electron microscopy images of a MP and b MagAmox 

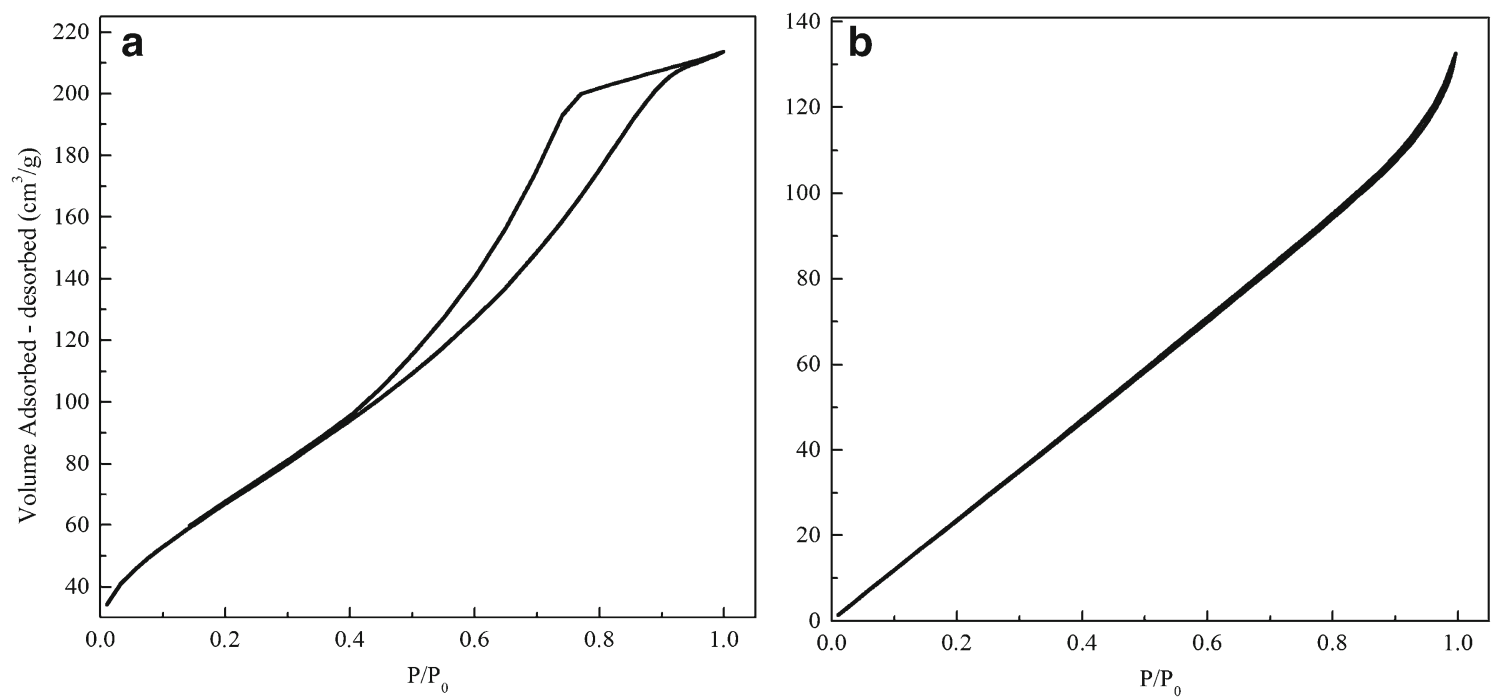

Fig. 4. Nitrogen adsorption-desorption isotherm. a MP and b MagAmox

magnet. The corresponding FTIR spectra are shown in Figs. 7a, b. For amoxicillin, major peaks were observed at

3170 and $3466 \mathrm{~cm}^{-1}$ (these peaks are related to amide $\mathrm{N}-\mathrm{H}$ and phenol $\mathrm{OH}$ stretching), $3043 \mathrm{~cm}^{-1}$ (C-H asymmetric

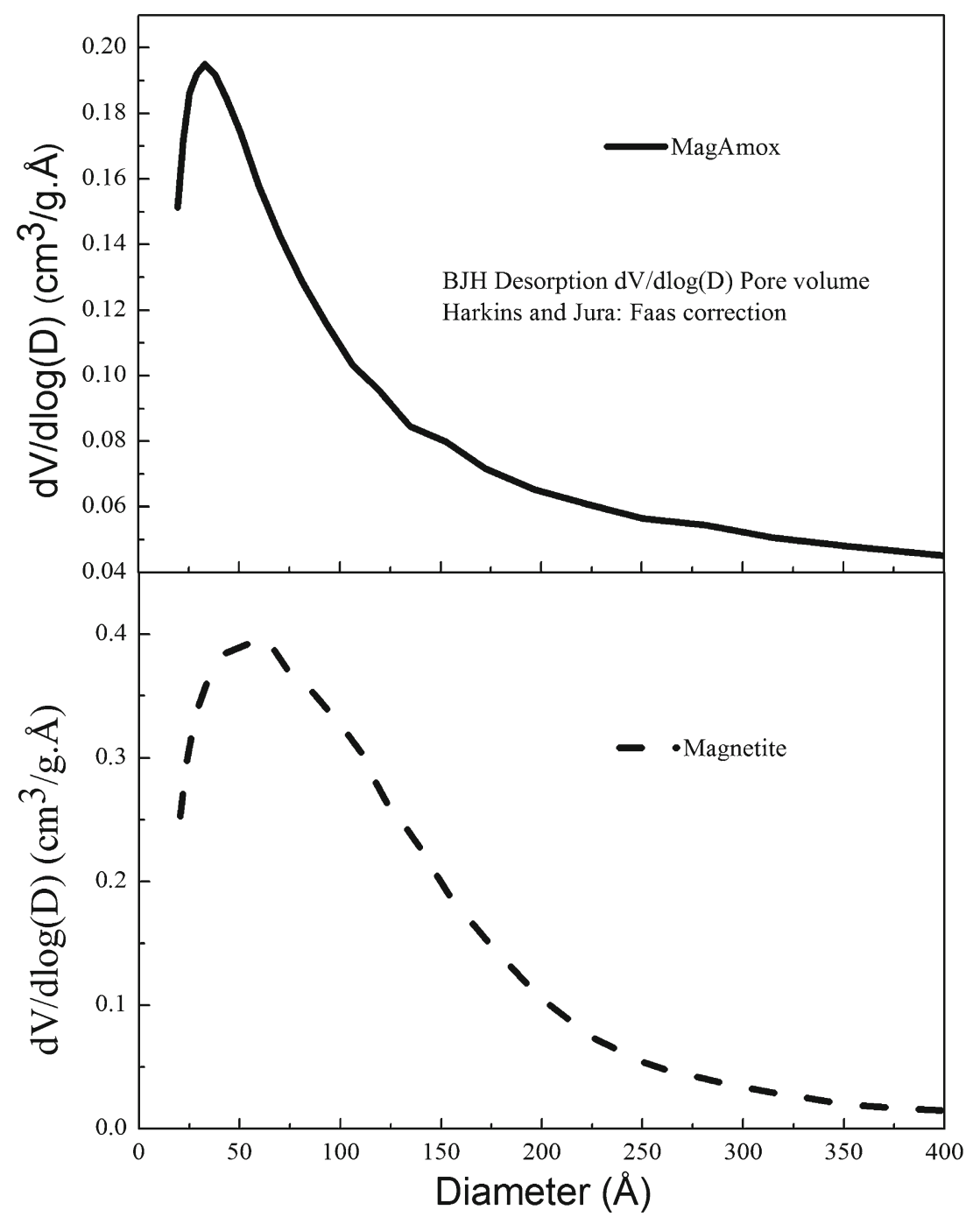

Fig. 5. Size distribution of the pores in MagAmox and magnetite aggregates (MP) obtained from the NSD isotherm 


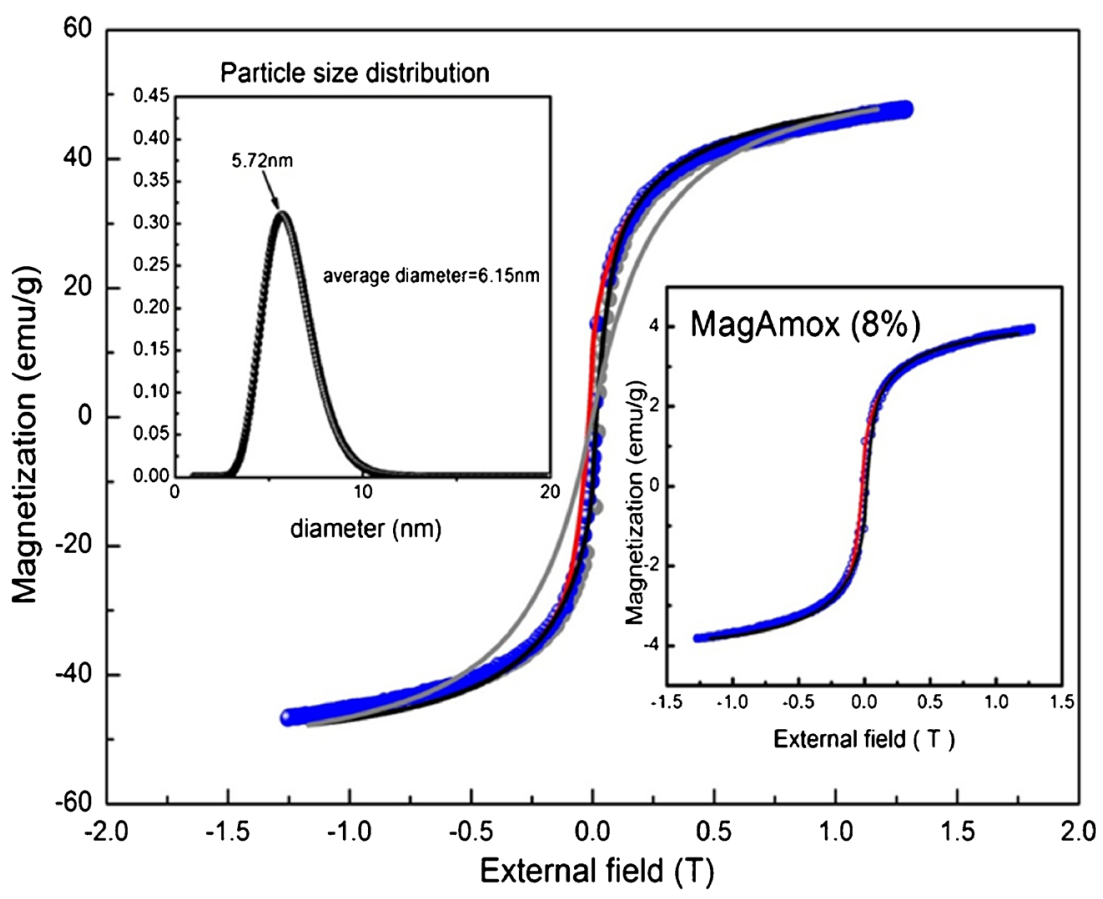

Fig. 6. Magnetization curves for MP and MagAmox samples. Black and blue open circles are related to the experimental data. The gray curve is the fitting to a Langevin function related to the size distribution in the inset. The black curve is the fit using a model that considers interaction between the nanoparticles. The inset shows the size distribution obtained from the model with magnetic interactions

stretch), $1777 \mathrm{~cm}^{-1}$ ( $\mathrm{C}=\mathrm{O}$ carbonyl stretching monomer), $1618 \mathrm{~cm}^{-1}$ (C-C stretching ring 2 and $\mathrm{N} 19 \mathrm{H}$ bending), $1516 \mathrm{~cm}^{-1}$ (benzene ring $\mathrm{C}=\mathrm{C}$ stretching), $1490 \mathrm{~cm}^{-1}(\mathrm{~N}-\mathrm{H}$ bend and $\mathrm{C}-\mathrm{N}$ stretch combination band), and $848 \mathrm{~cm}^{-1}(\mathrm{C}-$ $\mathrm{H}$ bending ring 2 , out of the plane) $(38,39)$. Characteristic peaks of amoxicillin (at 3466, 3043, 1618, and $848 \mathrm{~cm}^{-1}$ ) were also presented in the FTIR spectrum of MagAmox. This indicates that amoxicillin was successfully entrapped in the MagAmox. It should be highlighted that the $\mathrm{C}=\mathrm{O}$ stretch band corresponding to the carboxyl group, which was presented at $1777 \mathrm{~cm}^{-1}$ in the amoxicillin spectrum, was absent in the sMP/amoxicillin and MagAmox spectra. It is known that this band shifts to lower wavelength numbers when carbonyl groups interact with hydroxides present in carboxyl groups or on the surface of iron oxides particles. In fact, Eudragit ${ }^{\mathbb{B}} \mathrm{S} 100$ also exhibits a hydroxide and carbonyl groups in each repeating unit of its backbone, therefore, being able to interact with amoxicillin. In the sample sMP/ amoxicillin, the peaks at 2853 and $2922 \mathrm{~cm}^{-1}$ from the amoxicillin symmetric and asymmetric $\mathrm{CH} 2$ stretching modes, respectively. Furthermore, in Fig. 7b, the phenol $(\mathrm{OH})$ stretch in pure amoxicillin shifted to a band at $3453 \mathrm{~cm}^{-1}$ in sMP/amoxicillin suggests amoxicillin chemisorption onto the surface of iron oxide nanoparticles. These results explain the reduced pore diameter observed in the MagAmox sample in the NSD experiments and, therefore, are evidencing the chemisorption of $\mathrm{COOH}$ functional group from the amoxicillin onto the MP, as a carboxylate (40). Although some amoxicillin is chemisorbed onto the pores of the MP particles of MagAmox, the remaining content may be dispersed in the Eudragit ${ }^{\circledR} \mathrm{S} 100$ polymer network.

\section{Amoxicillin and Magnetite Content Assay}

Using the sulfosalicylic acid method, the iron content in MagAmox was $6.5 \%$. After converting this value to magnetite, the mass percentage in MagAmox was of $9 \%$, in good agreement with the MP fraction obtained from the magnetization measurements $(8 \%)$. The actual magnetite content in MagAmox is smaller than the nominal composition of the reagents added to the spray drier $(22 \%)$. This is a known feature of the spray-drying technique as a result of the distinct physical properties of the suspension components, which impacts the final yield. According to this study, the MagAmox final composition was $4.3 \pm 1.5 \%$ of amoxicillin, $87.0 \pm 2.3 \%$ of Eudragit, and $9.0 \pm 0.3 \%$ of magnetite.

\section{Drug Release Assay}

The release of amoxicillin from the MagAmox was evaluated at $\mathrm{pH} 1.2$ in a chloride acid solution and at $\mathrm{pH}$ 7.4 in a phosphate buffer. Data are shown in Fig. 8. The release rates from the microspheres at $\mathrm{pH} 1.2$ were significantly reduced when compared to the ones in the phosphate buffer. At $\mathrm{pH} 1.2$, polymer coating markedly prevented drug release. The small drug amount released at acidic $\mathrm{pH}$ may be related to amoxicillin located near to the MagAmox particle surface. Alternatively, the entire drug was released at $\mathrm{pH} 7.4$ in a prompt manner, as the polymer solubilized.

\section{Antimicrobial Tests of MagAmox}

It was noticed that MagEud (at a concentration of $100 \mu \mathrm{g} / \mathrm{mL}$ ) exhibited an antibacterial activity (inhibition 

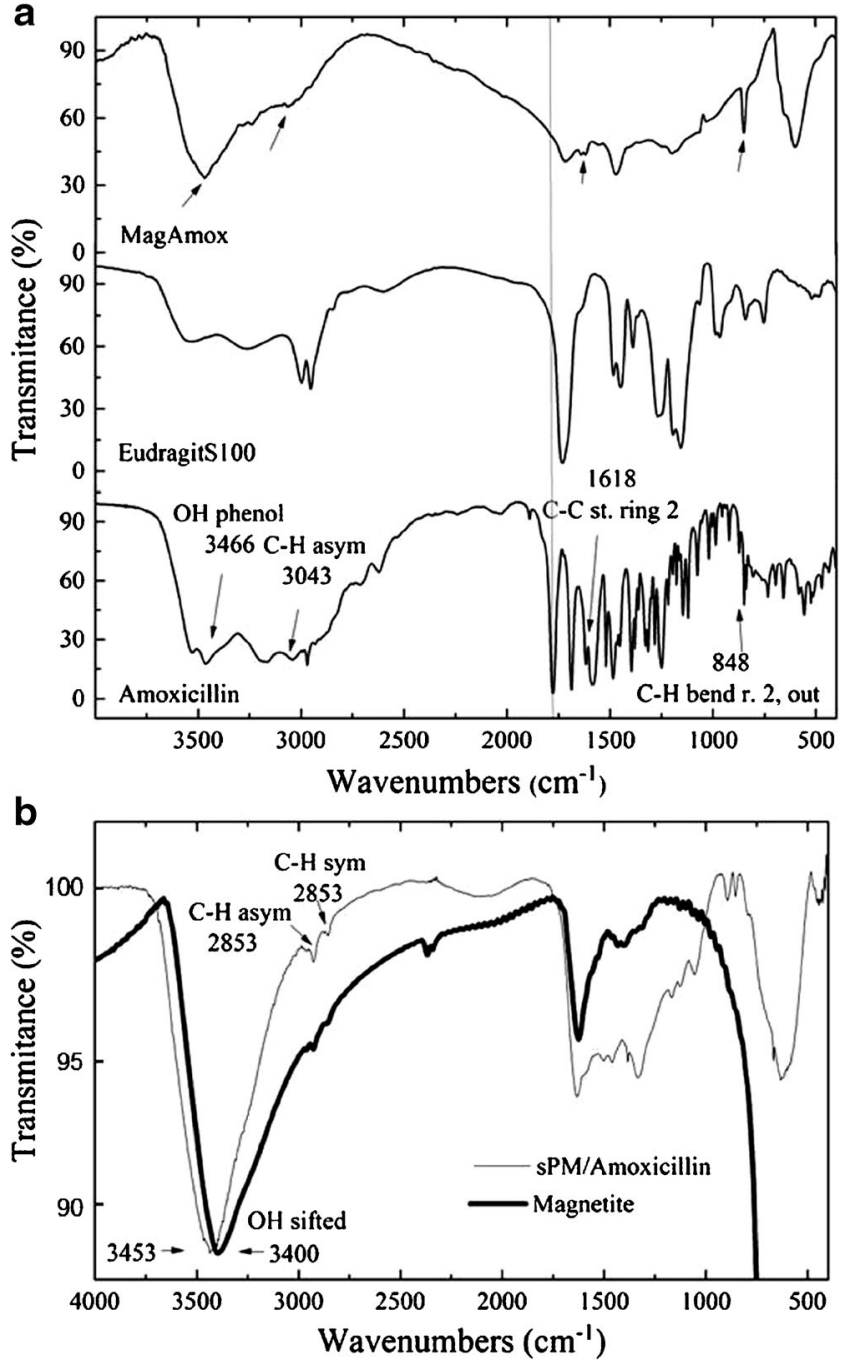

Fig. 7. FTIR spectra of a MagAmox, Eudragit ${ }^{\circledR}$ S100, and amoxicillin, vertical dashed line is at $1777 \mathrm{~cm}^{-1} \mathbf{b}$ sMP/amoxicillin and MP

zone of $13.0 \pm 1.0 \mathrm{~mm}$ ). Bactericidal activity of delivery systems partially relates to their concentration, size, and stability in the growth medium (41). Figure 9 indicates the

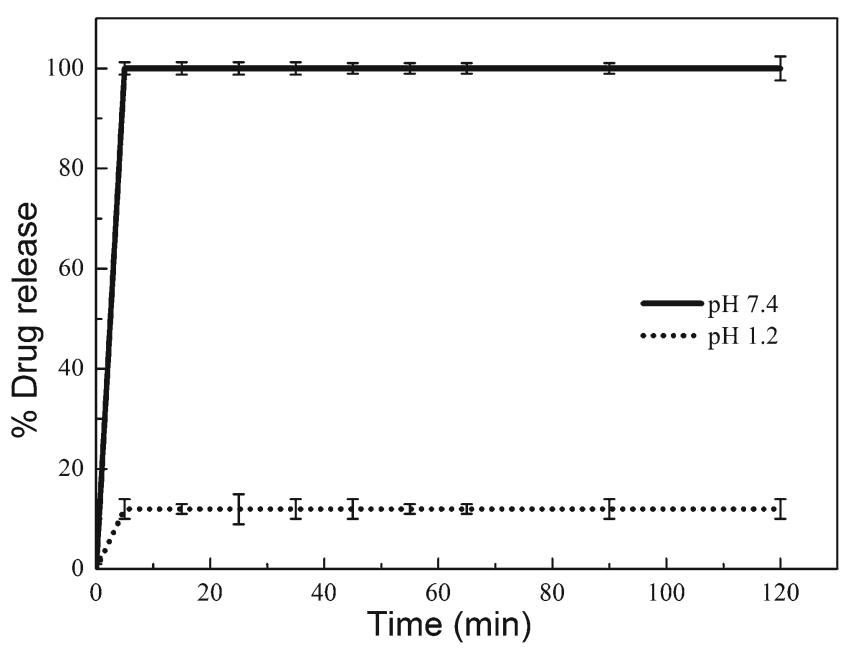

Fig. 8. Drug release of amoxicillin from MagAmox at different $\mathrm{pH}$ values

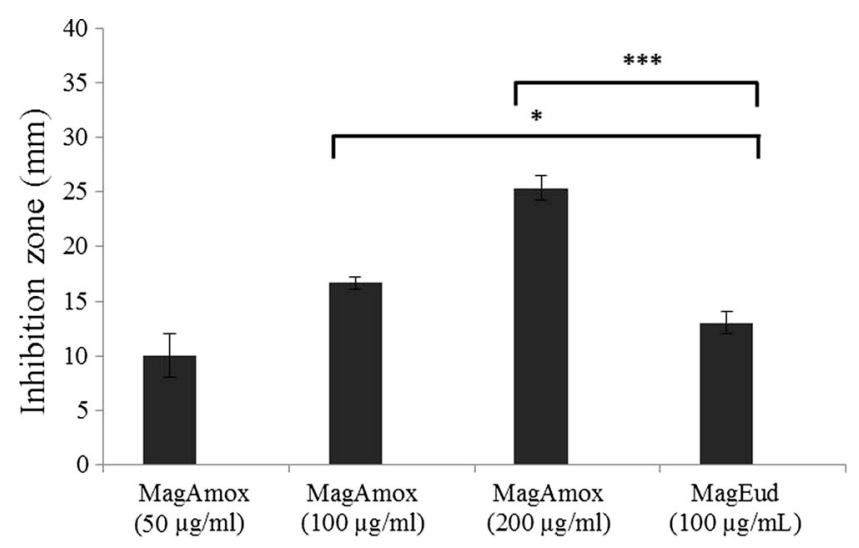

Fig. 9. Inhibition zones of MagAmox and MagEud. Different concentrations of MagAmox were used: 50,100, and $200 \mu \mathrm{g} / \mathrm{mL}$

zones of inhibition produced by different concentrations of MagAmox (50, 100, and $200 \mu \mathrm{g} / \mathrm{mL})$. The inhibition zones were found to be $10.0 \pm 2.0,16.7 \pm 0.6$, and $25.3 \pm 1.6 \mathrm{~mm}$, respectively. Inhibition was enhanced as concentration increased and it was statistically different from MagEud control.

\section{DISCUSSION}

In this work, mesoporous polymeric amoxicillin-loaded microparticles with a magnetic core were designed. The magnetite particles were produced by the co-precipitation method and subsequently coated with the Eudragit ${ }^{\circledR} \mathrm{S} 100$ and amoxicillin by spray-drying. The produced microparticles were characterized in terms of size, composition, magnetic properties, drug release, and antibacterial activity. Characterization data indicated that the obtained microparticles presented a mean diameter of $17.2 \pm 0.4 \mu \mathrm{m}$ and their final composition was $4.3 \pm 1.5 \%$ of amoxicillin, $87.0 \pm 2.3 \%$ of Eudragit, and $9.0 \pm 0.3 \%$ of magnetite.

Eudragit coating successfully endowed the particles with $\mathrm{pH}$ responsiveness. According to the drug release assay, there was a minimal amoxicillin release at gastric $\mathrm{pH}$ ( $\mathrm{pH} 1.2$ ) while total drug release was rapidly obtained at $\mathrm{pH}$ 7.4. It is often observed that controlled release formulations present an initial large drug bolus release immediately after placed in the release medium previously to reaching a stable profile rate. This phenomenon is known as burst release. This feature can be viewed from two perspectives: it is often regarded as a negative affect if long-term controlled release is desired, or, in certain cases, high dose rapid release may be of interest. For antibiotics, drug levels below the minimum inhibitory concentration (MIC) may induce bacterial resistance and enhance infectious complications. Concerning experiments at $\mathrm{pH} 1.2$, the rate of released drug was significantly reduced and the released drug amount may be related to amoxicillin located near to the MagAmox particle surface. This feature is interesting when it is necessary to attain drug protection against low $\mathrm{pH}$ values and drug release only at higher $\mathrm{pH}$ values. For example, for the therapy of infection induced by $H$. pylori, antibiotic protection from the acid degradation in the stomach is of importance (42). Eudragit prevented drug 
release at acidic $\mathrm{pH}$, protecting the drug, while disintegrating at and above neutral $\mathrm{pH}$ to enable the drug to act locally at a bactericidal concentration. Such $\mathrm{pH}$ responsiveness profile may be a main asset for deep mucus layer antimicrobial delivery in the treatment of peptic ulcers, considering that it may enable optimal drug delivery at the niche of $H$. pylori with neutral $\mathrm{pH}$. In fact, this is a very innovative approach as Eudragit ${ }^{\circledR} \mathrm{S} 100$ is most often used for colon release (43). To our knowledge, it is the first time that Eudragit coating is designed and tested in vitro for potential mucus-penetrating particles with a view to deep mucus targeted drug delivery.

In addition to the $\mathrm{pH}$ responsiveness, the microparticles produced herein are magnetic responsive, as attested by their magnetization curve. Such magnetic responsiveness is the basis of the mucus-penetrating potential of the designed microparticles. One important question to address is how deep an external magnetic field can act in the stomach in order to address the microparticles to the site of interest. This issue is a quite difficult to determine. For optimal results, there should be a magnetic clinical apparatus placed near the infection site (close to the abdomen surface) so that the magnetic force should be larger than the viscosity force.

Mucus constitutes a viscous, sticky, and elastic layer that traps and eliminates molecules and particles, precluding effective drug therapies $(8,9)$. Mucoadhesive systems (16, $44,45)$ have been widely investigated for gastric drug delivery. However, mucoadhesive system transit time depends on the physiological turnover time of mucus, which is of some hours. Additionally, mucoadhesive systems are not able to go through the mucus layer $(8,9)$. A current strategy to obtain mucus-penetrating particles is their coating with muco-inert low M.W. ( $2 \mathrm{kDa})$ polyethylene glycol polymer. Such particles were found to infiltrate human mucus with diffusivities that are only fourfold inferior to the ones obtained when comparing to data in pure water (46).

To the best of our knowledge, magnetic microparticles are herein, for the first time, suggested and tested in vitro as potential mucus-penetrating drug delivery systems for controlled drug delivery (Fig. 10). In this regard, it is important to mention that water availability in mucus layer for Eudragit ${ }^{\circledR} \mathrm{S} 100$ dissolution is a key point. Dissolution

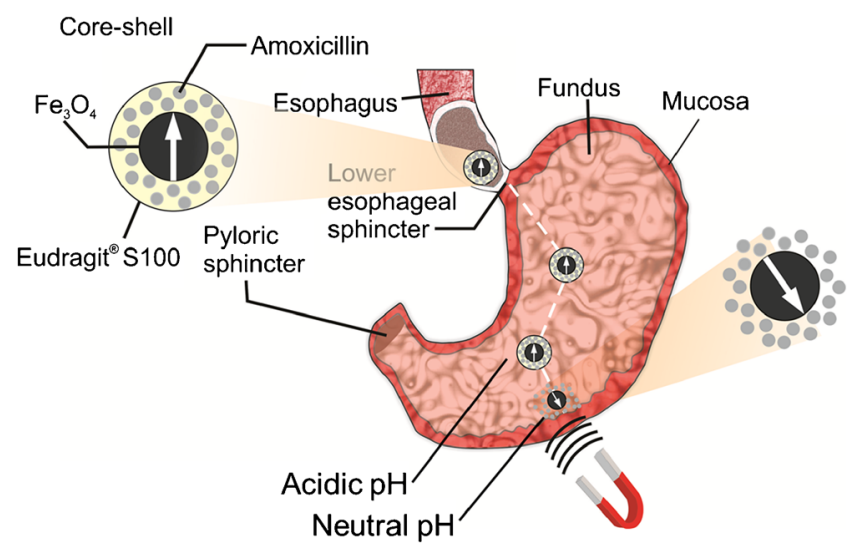

Fig. 10. Schematic representation of the $\mathrm{pH}$ and magnetic responsiveness of MagAmox for gastric antimicrobial therapy kinetics is expected to be slower in mucus, which does not mean that it will be prevented. Additionally, Eudragit ${ }^{\circledR} \mathrm{S} 100$ dissolution is not supposed to be total in order to achieve drug release. As dissolution will start, the formation of pores in Eudragit ${ }^{\circledR} \mathrm{S} 100$ capsules will take place enabling drug release onset through them. It is also important to mention that nanoparticles composed of Eudragit ${ }^{\circledR}$ S100 have already been proposed mucosal drug delivery (47). However, this approach differed from ours concerning the intended administration route (vaginal administration instead of oral administration in our case). Although in vivo experiments should still be performed, our study represents the first step towards a deep mucus targeted antimicrobial delivery in the treatment of peptic ulcers.

\section{CONCLUSION}

In this work, the preparation of the mesoporous polymer-coated amoxicillin microparticles, presenting a mean diameter of $17.2 \mu \mathrm{m}$, with superparamagnetic magnetite core was demonstrated. According to the drug release assay, a significant decrease on drug release at gastric $(\mathrm{pH}$ 1.2) compared to the higher $\mathrm{pH}$ was found. Therefore, it was shown that Eudragit coating successfully prevented the drug dissolution at low $\mathrm{pH}$. Regarding the oral administration of magnetic systems, this is an interesting feature, since the drug release takes place in response to the $\mathrm{pH}$ of the media enabling selective delivery of the drug in the deep mucous niche of $H$. pylori. Indeed, the antimicrobial activity of the system was attested for a model microorganism (M. luteus). Besides the antimicrobial properties and $\mathrm{pH}$ responsiveness, the designed particles were also magnetic field-responsive, as attested by magnetization curves. Magnetic field responsiveness is expected to constrain the penetration of the system across the mucus layer to reach bacterium niche by means of magnetic field gradient created by an external permanent magnet. Although in vivo tests are yet to be performed, the in vitro results obtained herein indicate that the unique features of the designed particles may hold great promises for deep mucus layer antimicrobial delivery in the treatment of peptic ulcers.

\section{ACKNOWLEDGEMENTS}

This research was partially supported by the Brazilian research agencies Coordenação de Aperfeiçoamento de Pessoal de Nível Superior (CAPES) and Conselho Nacional de Desenvolvimento Científico e Tecnológico (CNPq). The authors are grateful to the Núcleo de Petróleo de Gás Natural (NEPGN, UFRN) for the SEM images, to the Fundação Oswaldo Cruz (Fiocruz/RJ, Brazil) for the bacterial strain and to the Centro de Tecnologias Estratégicas do Nordeste (CETENE) for the NSD and BET/BJH analysis and to the Laboratório Central Dr. Almino Fernandes (LACEN-RN) for the microbiological analysis.

\section{COMPLIANCE WITH ETHICAL STANDARDS}

Conflict of Interest The authors declare that they have no conflict of interest. 


\section{REFERENCES}

1. Amieva MR, El-Omar EM. Host-Bacterial Interactions in Helicobacter pylori infection. Gastroenterology. 2008;134(1):30623. 385 .

2. Yoshiyama H, Nakazawa T. Unique mechanism of Helicobacter pylori for colonizing the gastric mucus. Microbes Infect. 2000;2(1):55-60.

3. Gerrits MM, van Vliet AH, Kuipers EJ, Kusters JG. Helicobacter pylori and antimicrobial resistance: molecular mechanisms and clinical implications. Lancet Infect Dis. 2006;6(11):699-709.

4. Archimandritis A, Avgerinos A, Nakos A, Viazis N, Skandalis N, Tzivras M. Open- label study of a regimen consisting of 1 week of lansoprazole, clarithromycin, and amoxicillin followed by 3 weeks of lansoprazole in healing peptic ulcer and eradicating Helicobacter pylori. Curr Ther Res. 2000;61(7):406-13.

5. Genta RM, Huberman RM, Graham DY. The gastric cardia in Helicobacter pylori infection. Hum Pathol. 1994;25(9):915-9.

6. Rajinikanth PS, Balasubramaniam J, Mishra B. Development and evaluation of a novel floating in situ gelling system of amoxicillin for eradication of Helicobacter pylori. Int J Pharm. 2007;335(1-2):114-22.

7. Cone RA. Barrier properties of mucus. Adv Drug Deliv Rev. 2009;61(2):75-85.

8. Plapied L, Duhem N, des Rieux A, Préat V. Fate of polymeric nanocarriers for oral drug delivery. Curr Opin Colloid Interface Sci. 2011;16(3):228-37.

9. Lai SK, Wang Y-Y, Hanes J. Mucus-penetrating nanoparticles for drug and gene delivery to mucosal tissues. Adv Drug Deliv Rev. 2009;61(2):158-71.

10. Jagdale SC, Agavekar AJ, Pandya SV, Kuchekar BS, Chabukswar AR. Formulation and evaluation of gastroretentive drug delivery system of propranolol hydrochloride. AAPS Pharm Sci Technol. 2009;10(3):1071-9.

11. Nama M, Gonugunta CSR, Veerareddy PR. Formulation and evaluation of gastroretentive dosage forms of clarithromycin. AAPS Pharm Sci Technol. 2008;9(1):231-7.

12. Hejazi R, Amiji M. Stomach-specific anti-H. pylori therapy. I: preparation and characterization of tetracyline-loaded chitosan microspheres. Int J Pharm. 2002;235(14112):87-94.

13. Oth M, Franz M, Timmermans J, Möes A. The bilayer floating capsule: a stomach-directed drug delivery system for misoprostol. Pharm Res. 1992;9(3):298-302.

14. Klausner EA, Lavy E, Friedman M, Hoffman A. Expandable gastroretentive dosage forms. J Control Release. 2003;90(2):143-62.

15. Chen J, Blevins WE, Park H, Park K. Gastric retention properties of superporous hydrogel composites. J Control Release. 2000;64(1-3):39-51.

16. Higo S, Ori K, Takeuchi H, Yamamoto H, Hino T, Kawashima Y. A novel evaluation method of gastric mucoadhesive property in vitro and the mucoadhesive mechanism of tetracyclinesucralfate acidic complex for eradication of Helicobacter pylori. Pharm Res. 2004;21(3):413-9.

17. Carriço AS, Silva ÉL, Medeiros AC, Egito EST, Carvalho JF, Pontes TRF. Sistema magnético para vetorização de antibióticos para tratamento de infecções por Helicobacter pylori. Brasil 2012 26/06/2012.

18. Silva AKA, Silva-Freitas É, Carvalho J, Pontes TF, Araújo-Neto $\mathrm{R}$, Silva KL, et al. Magnetic particles in biotechnology. Drug targeting to tissue engineering. Rijeka. InTeck; 2012.

19. Saravanan M, Balaji A, Kavitha P, Kingsley J. Controlled delivery of ranitidine in the stomach using magnetic field. W Indian Med J. 2009;58:87-91.

20. Pankhurst QA, Connolly J, Jones SK, Dobson J. Applications of magnetic nanoparticles in biomedicine. J Phys D Appl Phys. 2003;36:R167-81.

21. Silva AKA, Silva ÉL, Carvalho JF, Pontes TRF, Araújo-Neto RP, Carriço AS, et al. Drug targeting and other recent applications of magnetic carriers in therapeutics. Key Eng Mater. 2010;441:357-78.

22. Kaminski MD, Rosengart AJ. Detoxification of blood using injectable magnetic nanospheres: a conceptual technology description. J Magn Magn Mater. 2005;293(1):398-435 403.
23. Paipa C, Mateo M, Godoy I, Poblete E, Toral MI, Vargas T. Comparative study of alternative methods for the simultaneous determination of $\mathrm{Fe}^{+3}$ and $\mathrm{Fe}^{+2}$ in leaching solutions and in acid mine drainages. Miner Eng. 2005;18(11):1116-9.

24. Massart R. Preparation of aqueous magnetic liquids in alkaline and acidic media. IEEE Trans Magn. 1981:1247-8.

25. Gharsallaoui A, Roudaut G, Chambin O, Voilley A, Saurel R. Applications of spray-drying in microencapsulation of food ingredients: an overview. Food Res Int. 2007;40(9):1107-21.

26. Pons M-N, Vivier H, Delcour V, Authelin J-R, Paillères-Hubert L. Morphological analysis of pharmaceutical powders. Powder Technol. 2002;128(2-3):276-86.

27. Barrett E, Joyner L, Halenda P. The determination of pore volume and area distributions in porous substances. I. Computations from nitrogen isotherms. J Am Chem Soc. 1951:73:373-80.

28. Silva-Freitas É, Carvalho J, Pontes TF, Araújo-Neto R, Carriço A, Egito E. Magnetite content evaluation on magnetic drug delivery systems by spectrophotometry: a technical note. AAPS Pharm Sci Technol. 2011;12(2):521-4.

29. Bauer A, Kirby W, Scherris J, Turck M. Antibiotic susceptibility testing by a standardized single disk method. Am J Clin Pathol. 1966;45(4):493-6.

30. Berry V, Jennings K, Woodnutt G. Bactericidal and morphological effects of amoxicillin on Helicobacter pylori. Antimicrob Agents Chemother. 1995;39(8):1859-61.

31. de Cassia Bergamaschi C, Motta RH, Franco GC, Cogo K, Montan MF, Ambrosano GM, et al. Effect of sodium diclofenac on the bioavailability of amoxicillin. Int J Antimicrob Agents. 2006;27(5):417-22.

32. Morales MA, Mascarenhas AJS, Gomes AMS, Leite CAP, Andrade HMC, de Castilho CMC, et al. Synthesis and characterization of magnetic mesoporous particles. J Colloid Interface Sci. 2010;342(2):269-77.

33. Z-q F, Wang L-j, Li D, Adhikari B. Effects of partial gelatinization on structure and thermal properties of corn starch after spray drying. Carbohydr Polym. 2012;88(4):1319-25.

34. Vallet-Reg1 M, Doadrio JC, Doadrio AL, Izquierdo-Barba I, Pérez-Pariente J. Hexagonal ordered mesoporous material as a matrix for the controlled release of amoxicillin. Solid State Ionics. 2004;172(1-4):435-9.

35. Ahuja G, Pathak K. Porous carriers for controlled/modulated drug delivery. Indian J Pharm Sci. 2009;71(6):599-607.

36. Zhang $Y$, Wang J, Bai X, Jiang $T$, Zhang $Q$, Wang $S$. Mesoporous silica nanoparticles for increasing the oral bioavailability and permeation of poorly water soluble drugs. Mol Pharm. 2012;9(3):505-13.

37. Salonen J, Laitinen L, Kaukonen AM, Tuura J, Björkqvist M, Heikkilä T, et al. Mesoporous silicon microparticles for oral drug delivery: loading and release of five model drugs. J Control Release. 2005;108(2-3):362-74.

38. Bebu A, Szabó L, Leopold N, Berindean C, David L. IR, Raman, SERS and DFT study of amoxicillin. J Mol Struct. 2011;993(1-3):52-6.

39. Castillo-Ortega MM, Nájera-Luna A, Rodríguez-Félix DE, Encinas JC, Rodríguez-Félix F, Romero J, et al. Preparation, characterization and release of amoxicillin from cellulose acetate and poly(vinyl pyrrolidone) coaxial electrospun fibrous membranes. Mater Sci Eng C Mater Biol Appl. 2011;31(8):1772-8.

40. Zhang $\mathrm{L}, \mathrm{He} \mathrm{R}, \mathrm{Gu} \mathrm{H}-\mathrm{C}$. Oleic acid coating on the monodisperse magnetite nanoparticles. Appl Surf Sci. 2006;253(5):2611-7.

41. Azam A, Ahmed AS, Oves M, Khan MS, Habib SS, Memic A. Antimicrobial activity of metal oxide nanoparticles against Gram-positive and Gram-negative bacteria: a comparative study. Int J Nanomedicine. 2012;7:6003-9.

42. Erah PO, Goddard AF, Barrett DA, Shaw PN, Spiller RC. The stability of amoxycillin, clarithromycin and metronidazole in gastric juice: relevance to the treatment of Helicobacter pylori infection. J Antimicrob Chemother. 1997;39(1):5-12.

43. Khan MZI, Prebeg Ž, Kurjaković N. A pH-dependent colon targeted oral drug delivery system using methacrylic acid copolymers: I. Manipulation of drug release using Eudragit ${ }^{\circledR}$ L100-55 and Eudragit ${ }^{\circledR}$ S100 combinations. J Control Release. 1999;58(2):215-22. 
44. Karn PR, Vanić Z, Pepić I, Škalko-Basnet N. Mucoadhesive liposomal delivery systems: the choice of coating material. Drug Dev Ind Pharm. 2011;37(4):482-8.

45. Alam N, Beg S, Rizwan M, Ahmad A, Ahmad FJ, Ali A, et al. Mucoadhesive elementary osmotic pump tablets of trimetazidine for controlled drug delivery and reduced variability in oral bioavailability. Drug Dev Ind Pharm. 2015;41(4):692-702.
46. Lai SK, O'Hanlon DE, Harrold S, Man ST, Wang Y-Y, Cone R, et al. Rapid transport of large polymeric nanoparticles in fresh undiluted human mucus. Proc Natl Acad Sci U S A. 2007;104(5):1482-7. 500.

47. Yoo JW, Giri N, Lee CH. pH-sensitive Eudragit nanoparticles for mucosal drug delivery. Int J Pharm. 2011;403:262-7. 